Review

\title{
Sphingosine-1-phosphate Signaling in Endothelial Activation
}

\author{
Harunobu Ozaki, Timothy Hla, and Menq-Jer Lee \\ Center for Vascular Biology, Department of Physiology, University of Connecticut Health Center, Farmington, CT, \\ USA.
}

\begin{abstract}
The signaling and functions of the Endothelial Differentiation Gene (EDG) family of G protein-coupled receptors have been extensively elucidated. All the members of EDG family were shown to be receptors for lysosphingolipids or lysophospholipids. EDG-1, the prototype of EDG family receptors, is a high affinity receptor for serum-borne bioactive lipid, Sphingosine-1-phosphate (S1P). S1P, secreted by thrombotic platelets, has been shown to regulate a variety of cellular responses, including survival, cytoskeletal remodeling, chemotaxis etc, via the activation of cell surface EDG receptors. Recently, a novel function of S1P in modulating angiogenic response has been demonstrated. This review will focus on S1P/ EDG-1 signaling in endothelial activation, in particular in the S1P-mediated adherens junctions assembly and chemotaxis in endothelial cells. J Atheroscler Thromb, 2003; 10: 125-131.
\end{abstract}

Key words: EDG receptor, Adherens junction, Chemotaxis, Angiogenesis

\begin{abstract}
Angiogenesis, the process of new blood vessel formation, is important in embryonic development and normal physiological events, such as fetal vasculogenesis, wound healing, and corpus luteum formation $(1,2)$. Dysregulated angiogenesis is involved in pathological conditions, e.g. solid tumor growth and diabetic retinopathy (3). The process of angiogenesis is regulated by soluble growth factors (4), and extracellular matrix-derived signals (5), among others. Moreover, it is generally thought that angiogenesis in vivo is achieved by a balance between positive (angiogenic) and negative (antiangiogenic) factors $(1,4,6)$. For example, Ferrara's group and others $(4,7)$ showed that tumors secrete vascular endothelial growth factor (VEGF), a specific angiogenic factor, which stimulated angiogenesis. In addition, Folkman's group showed that primary tumors inhibit distant metastases via the production of angiogenesis inhibitors such as angiostatin and endostatin $(6,8)$.

The process of angiogenesis is initiated by degradation
\end{abstract}

Address for correspondence: Menq-Jer Lee, Ph.D, Center for Vascular Biology, Department of Physiology, University of Connecticut Health Center, Farmington, CT 06030, USA

E-mail: mlee@sun.uchc.edu

Received January 10, 2003.

Accepted for publication February 20, 2003. of the basement membrane, cell invasion, directed cell migration, followed by the proliferation of endothelial cells, differentiation, morphogenesis, and finally the establishment of a new vasculture. However, the molecular mechanisms underlying this highly orchestrated process have remained elusive. Folkman and Haudenschild (9) showed that isolated endothelial cells in culture can form a complete vascular structure. Following this important discovery, cultured endothelial cells have become a widely used in vitro model system to study angiogenesis. Furthermore, Montesano and Orci (10) showed that tumor promotor, phorbol 12 myristate 13-acetate (PMA), was a potential angiogenic factor in vitro, inducing tubule formation of endothelial cells cultured in 3-dimensional collagen gel. To study genes involved in the differentiative aspects of angiogenesis; EDG-1 (endothelial differentiation gene-1), a PMA-induced gene, was isolated from cultured endothelial cells (11). Northern blotting analysis indicated that EDG-1 was rapidly and transiently induced by PMA in endothelial cells and was superinduced in the presence of protein synthesis inhibitor, cycloheximide. Thus, EDG-1 is a member of the immediately-early genes. Since immediately-early genes are important for cell growth and differentiation (12), we initially hypothesized that PMA-induced EDG-1 may regulate endothelial differentiation. 


\section{$\mathrm{G}_{\mathrm{i}}$ is a major $\mathbf{G} \alpha$ subunit coupled to EDG-1 G-protein-coupled receptor}

Sequence analysis indicated that EDG-1 encodes a novel G protein-coupled receptor (GPCR) with seven hydrophobic transmembrane domains (11). Immediate questions involve which heterotrimeric $\mathrm{G}$ proteins are coupled to EDG-1, what signals are mediated by EDG-1, what the ligand is for EDG-1, and what the physiological functions of EDG-1 in vivo are?

It has been well documented that the third intracellular loop $\left(\mathrm{i}_{3}\right)$ of a GPCR is important for interacting with its cognate G proteins (13). Therefore, we constructed a fusion protein in which the intracellular loop $3\left(\mathrm{i}_{3}\right)$ domain of EDG-1 was linked to the C-terminus of glutathione S-transferase (GST) (14). By affinity chromatography, we observed that the pertussis toxin-sensitive, but not cholera toxin-sensitive, G proteins specifically interacted with GST-EDG-1-i $\mathrm{i}_{3}$. This interaction was inhibited in the presence of GTP $\mathcal{S}$, suggesting that this in vitro interaction is physiologically relevant. The $G$ proteins bound to EDG- $1-\mathrm{i}_{3}$ immunoreacted with anti-G $\alpha$ antibodies. The $\mathrm{G} \alpha$ specificity was further confirmed by (i) the $G_{i} \alpha$ polypeptides which were co-immunoprecipitated with intact EDG-1 GPCR (14), and (ii) yeast's two hybrid interaction system (14). Also, we demonstrated that EDG-1 GPCR was capable of activating $\mathrm{G}_{\mathrm{i}} \alpha$-mediated signals, including mitogen-activated protein (MAP) kinase (14), phospholipase A2 (14), and inhibition of adenylate cyclase (15). The notion that EDG-1 GPCR specifically coupled to $G_{i} \alpha$ heterotrimeric $G$ protein was further confirmed by a recent study, in which only chimerical Giq was able to transduce EDG-1 signaling to induce intracellular $\mathrm{Ca}^{+2}$ mobilization in Xenopus Oocytes (16).

\section{EDG-1 is a high affinity receptor for the serum- borne bioactive lipid Sphingosine-1-phosphate (S1P)}

Subsequently, identifying the physiological ligand and signaling relevant for EDG-1 GPCR became a formidable and urgent task. With minimal information available for EDG GPCRs, initial phylogram analysis indicated that EDG-1 was most closely related to the cannabinoid receptor family. Thus, we hypothesized that the EDG-1 ligand might be lipid-related. In the beginning, we utilized the $G_{i} /$ MAP kinase pathway to screen the ligand for EDG-1 by using EDG-1 transiently overexpressed cells. However, the results obtained were difficult to interpret due to the presence of endogenous EDG-1 and other $\mathrm{G}_{\mathrm{i}}$-coupled receptors in many cell types. Therefore, we examined a variety of cells in an attempt to find cell lines which express extremely low levels of EDG-1 GPCRs. Those lines were utilized to establish EDG-1 stable transfectants, which were then used to screen for EDG-1 ligand. Among the lines screened, we found that human embryonic kidney 293 (HEK293) fibroblast-like cells have barely detectable EDG-1 mRNA. Strikingly, all the EDG-1 stably overexpressed HEK293 clones (HEK293EDG-1) exhibited a distinct morphology (17), which will be discussed in detail in the following sections. Briefly, HEK293EDG-1 cells were tightly aggregated and formed network-like structures similar to the tubular structure in differentiated endothelial cells (17). However, why EDG-1 overexpression resulted in the formation of tubular-like morphology is unclear?

Since EDG-1 is derived from endothelial cells which are exposed to the blood stream in vivo, we hypothesized that the EDG-1 ligand is present in serum and ligand/ EDG-1 interaction results in the formation of aggregated morphology in HEK293EDG-1 cells. To test this hypothesis, fetal bovine serum (FBS), which is routinely used for cell culture, was subjected to various manipulations (17). Heat-denatured FBS $\left(95^{\circ} \mathrm{C}\right.$ for $\left.1 \mathrm{~h}\right)$ still contained an aggregation-inducing ability, indicating that serumborne EDG-1 ligand is very heat-stable. In contrast, the aggregation-inducing ability of FBS was diminished when serum was pre-incubated with charcoal to remove serum-borne bioactive lipids (17). Moreover, the acideluant of charcoal bound serum lipids was capable of inducing aggregation specifically in HEK293EDG-1 cells, but not in control cells. Collectively, these data suggest that EDG-1 ligand is a bioactive lipid present in serum.

Therefore, we utilized the morphological aggregation of HEK293EDG-1 cells as a readout for screening EDG-1 ligand. Among available lipids, we found that Sphingosine-1 phosphate (S1P) induced EDG-1 cells aggregation effectively (17). Other lipid analogs, such as sphingosine, sphingomyelin, ceramide, ceramide-1phosphate, lysophosphatidylserine, lysophosphatidyl ethanolamine, lysophosphatidyl inositol, lysophosphatidyl choline, leukotriene B4 and C4, platelet activating factor, anandamide, 12-hydroxyeicosatetraenoic acid (12HETE), 5-HETE, 15-HETE, and 13-hydroxydodecanoic acid, were ineffective at concentrations as high as 50 $\mu \mathrm{M}$. Furthermore, C3 exotoxin, an inhibitor of Rho small GTPase, completely inhibited S1P-induced aggregation, suggesting a requirement for the small GTPase Rho (17). Several lines of evidences supported the notion that $\mathrm{S} 1 \mathrm{P}$ is a high-affinity ligand for EDG-1. First, radiolabelled [ $\left.{ }^{32} \mathrm{P}\right] \mathrm{S} 1 \mathrm{P}$ binding was observed only in HEK293EDG-1 cells, whereas binding was negligible in vector-only transfected control cells (17). This $\left.{ }^{32} \mathrm{P}\right] \mathrm{S} 1 \mathrm{P}$ binding was inhibited in the presence of excess nonradioactive S1P but not by other lipid analogs, indicating that the binding was highly specific. Scatchard plot analysis showed that the apparent Kd of EDG-1 for S1P is $8.1 \mathrm{nM}$. S1P is present in serum with a concentration much greater than the Kd of EDG-1 (18). Secondly, S1P was able to activate MAP kinase directly via the EDG-1 receptor and $G_{1} \alpha$ subunit. Thirdly, S1P induced EDG-1 receptor phosphorylation. Fourthly, EDG-1 receptor was internalized into 
intracellular vesicles specifically by incubating with S1P at $37^{\circ} \mathrm{C}$. Together, these results established formally that S1P is a high-affinity ligand for EDG-1. In agreement, Zondag et al. showed that S1P/ EDG-1 was able to inhibit adenylate cyclase and activate MAP kinase in a $\mathrm{G}_{\mathrm{i}}$-dependent manner (19).

S1P, a serum-borne bioactive lipid released from activated platelets $(18,20)$, is thought to be responsible for many biological activities of serum. Also, S1P has been demonstrated to regulate a wide range of cellular responses, including proliferation, platelet aggregation, stress fiber formation, neurite retraction, cell rounding, tumor cell migration, among others $(21,22)$. Moreover, it has been shown that S1P regulated most, if not all, of these responses by activating specific G-protein coupled receptors present on the cell surface of numerous cell types $(21,22)$. Our data collectively showed that EDG-1 is a high affinity receptor for S1P. Following the identification of ligand, the physiological functions of S1P/ EDG1 signaling have been elucidated from various laboratories. In this report, we will summarize the recent efforts to determine the S1P/ EDG-1 signaling on endothelial cells. Particularly, the assembly of adherens junctions and chemotaxis will be the main themes of this review.

\section{S1P/ EDG-1 signaling in adherens junctions assembly}

As mentioned above, all the EDG-1 stably overexpressed HEK293 clones (HEK293EDG-1) exhibited a distinct morphology (17). The control vector transfected cells (HEK293pCDNA) were evenly distributed at day 1, and reached confluency at day 3 after plating. In contrast, HEK293EDG-1 cells were tightly aggregated at day 1 , and formed network-like structures at day 3 after plating (Fig. 1). This distinct morphology of HEK293EDG-1 cells was similar to the tubular structure of differentiated endothelial cells, and thus was termed morphogenetic differentiation. Since EDG-1 was derived from endothelial cells which are exposed to the blood stream in vivo, we proposed that the EDG-1 ligand was present in serum and ligand/ EDG-1 interaction resulted in morphogenetic differentiation. By critically examining serum components, EDG-1 ligand was pinpointed to be a serum-borne bioactive lipid (17). Subsequently, we found that serum borne bioactive lipid sphingosine-1-phosphate (S1P) specifically induced morphogenetic differentiation of HEK293EDG-1 cells. Furthermore, we observed that HEK293EDG-1 cells aggregated strongly in suspension, whereas HEK293pCDNA cells did not (17). This aggre-
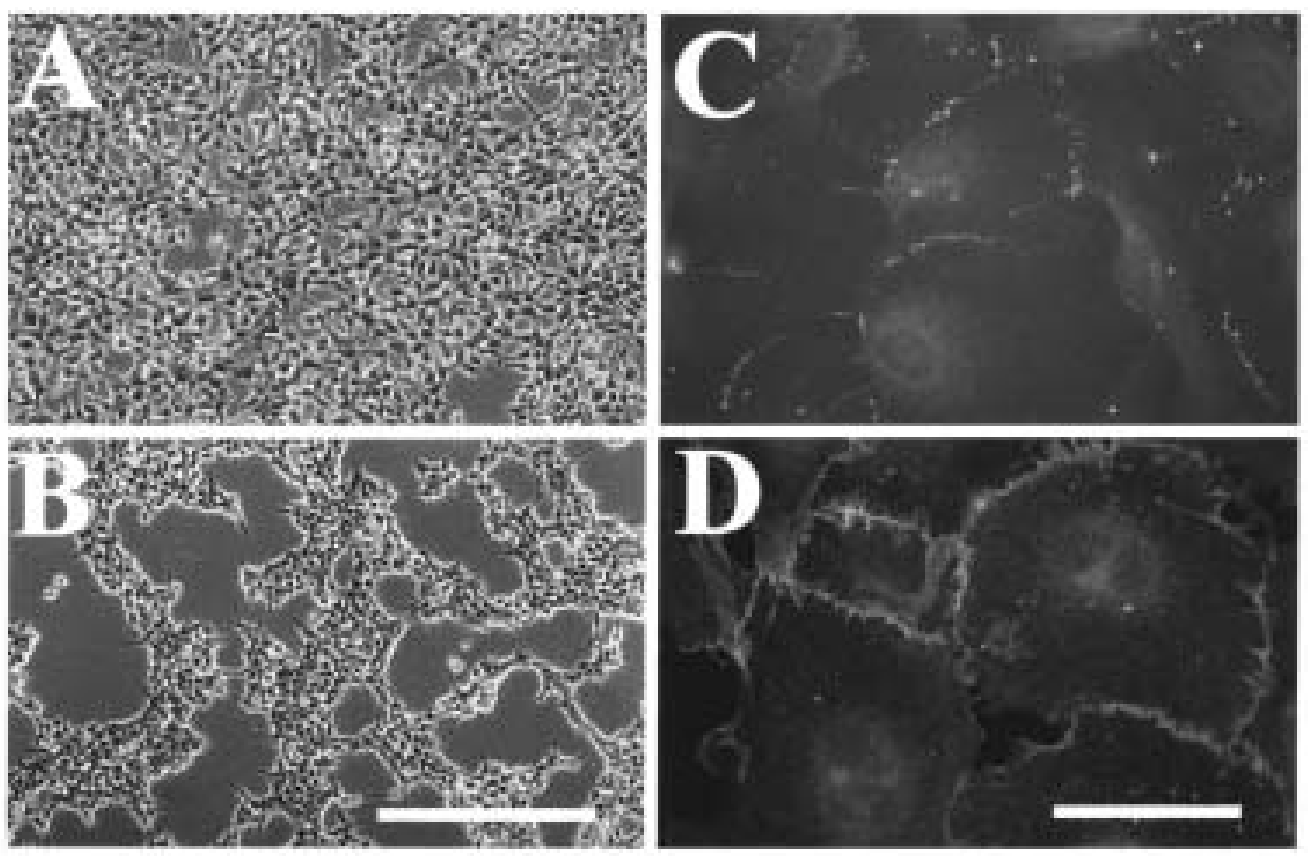

Fig. 1. S1P/ EDG-1 signaling induce morphogenetic differentiation and adherens junction assembly. HEK293 cells were stably overexpressed pCDNA (A) or EDG-1 (B) plasmid. Note that the EDG-1 expression results in aggregated, network-like morphology. HUVEC cells were treated without (C) or with (D) S1P, followed by immunostaining with anti-VE-cadherin. Note that the dramatic increase of VE-cadherin localization at cell-cell junctions in endothelial cells after S1P stimulation. Scale bars in $\mathrm{B}$ and $\mathrm{D}$ are 56 and $13.4 \mu \mathrm{M}$, respectively. 
gation was $\mathrm{Ca}^{+2}$-dependent, and was subsequently shown to be mediated by cadherin based adhesion mechanisms (23). The expression of P-and E-cadherins was increased in HEK293EDG-1 cells; whereas the expression of cytoplasmic cadherin-associated proteins, such as $\alpha-, \beta$-, and $\gamma$-catenins, was not altered. Electron microscopy analysis showed that HEK293EDG-1 cells had abundant well-developed adherens junction-like structures. In addition, the expression of P-cadherin in HEK293EDG-1 cells was enhanced dose-dependently by S1P treatment. Also, the Rho family of small guanosine triphosphatase (GTPase) was required for S1P/ EDG-1 induced cadherin expression and formation of adherens junctions, consistent with early observation that the Rho and Rac are required for the establishment of cadherindependent cell-cell contacts (24). These data together suggest that S1P/ EDG-1 signaling may function in regulating the biogenesis and/ or maintenance of the adherens junctional complexes.

We next investigated the physiological relevance of adherens junctions assembly regulated by S1P/ EDG-1 signaling. Human umbilical vein endothelial cells (HUVEC) express abundant EDG-1 and a much lower level of EDG3 , whereas the EDG-5 S1P receptor is barely detected (25). Treatment of endothelial cells with S1P resulted in dramatic increase of VE-cadherin, $\alpha-, \beta-$, and $\gamma$-catenin localization at cell-cell junctions (Fig. 1). Confocal immunofluorescence microscopy indicated that S1P treatment increased the localization of VE-cadherin into discontinuous structures at cell-cell contact regions, suggesting that S1P induced the formation of adherens junctions (25). Treatment with related lipids (sphingosine, sphingomyelin, ceramide, ceramide-1-phosphate) that do not interact with S1P receptors had no effect. Also, direct microinjection of S1P (ranging from $500 \mathrm{nM}$ to 500 $\mu \mathrm{M}$ ) into the cytoplasm did not increase the immunoreactivity of VE-cadherin and catenins at cell-cell junctions. Formation of mature adherens junctions requires homophilic binding of intercellular cadherins, association with cytoplasmic polypeptides, and attachment to the cytoskeleton, which ultimately results in the partitioning of cadherin molecules into the detergent-insoluble fraction (26). Fractionation of HUVEC cell lysates showed that S1P-induced, in a dose- and time-dependent manner, an increase in the amount of VE-cadherin in the Triton $X-100$ insoluble fraction; however, the overall level of protein was not altered. Furthermore, S1P significantly increased the $\alpha$-catenin and VE-cadherin polypeptides present in the $\gamma$ - and $\beta$-catenin immunoprecipitates (25).

To determine if Rho and Rac small GTPases were required for S1P-induced adherens junction assembly, C3 exoenzyme and dominant-negative N17Rac polypeptide were microinjected into HUVEC cells. Microinjection of C3 and N17Rac dramatically diminished S1P-induced VE-cadherin and $\beta$-catenin localization at cell-cell junc- tions (25). These data suggest that S1P-induced Rho and Rac activation was required for adherens junction assembly in HUVEC. Next, we examined the involvement of the EDG-1 and -3 subtypes of S1P receptors in the assembly of adherens junctions. For this, antisense phosphothioate oligonucleotides (PTO) specific for blocking the expression of EDG-1 and -3 receptors were developed (25). Subsequently, the EDG-1 or EDG-3 specific PTOs were microinjected into HUVEC, and both EDG-1 and -3 antisense PTOs were able to inhibit the S1P-induced VE-cadherin localization at cell-cell junctions (25). In contrast, neither the complementary nor the scrambled sequence of EDG-1 and -3 oligonucleotides inhibited VE-cadherin assembly significantly. Together, these results indicated the extracellular action of S1P via the EDG-1 and EDG-3 receptors transduced signals through the Rac and Rho small GTPases to regulate the assembly of adherens junctions in endothelial cells. In agreement, Garcia et al. (27) showed that S1P treatment resulted in rapid and sustained increases in endo-thelial monolayer barrier integrity, and reversed the thrombin-elicited endothelial barrier dysfunction. S1Pmediated endothelial barrier enhancement was dependent upon EDG receptor and Rho, Rac small GTPases.

It has been demonstrated that S1P signaling functioned as a novel angiogenic modulator both in cultured endothelial cells and in animals $(25,28)$. For example, S1P dosedependently promoted the morphogenesis of HUVEC and bovine microvascular endothelial cells into capillary-like networks on matrigel, which is a widely used angiogenic assay in vitro (29). Inactivation of the heterotrimeric $\mathrm{G}_{\mathrm{i}}$ protein by pertussis toxin abrogated the S1P-induced morphogenesis (25). Furthermore, the anti-VE-cadherin blocking monoclonal antibody (30) inhibited S1P-induced morphogenesis in a dose-dependent manner. Also, EDG1 and EDG-3 antisense PTO attenuated S1P-induced HUVEC morphogenesis. Coadministration of both PTOs reduced morphogenesis in an additive manner. In contrast, similar doses of EDG-1, -3 scrambled or sense sequences or the EDG-5 antisense PTO failed to block the S1P-induced endothelial cell morphogenesis. These data indicatd that S1P activated EDG-1 and EDG-3 receptors on endothelial cells, resulting in the activation Rho-/Rac-mediated VE-cadherin assembly into adherens junctions which was important for endothelial cell morphogenesis into capillary-like networks. This observation is consistent with other studies implicating the importance of VE-cadherin in endothelial cell morphogenesis $(30,31)$.

\section{S1P/ EDG-1 signaling in endothelial cell migration} Angiogenesis, a highly regulated process, includes orderly events such as proliferation, migration, and differentiation. Recently, several studies have demonstrated that $\mathrm{S} 1 \mathrm{P}$ is a potent chemoattractant for endothelial cells, and more effective than VEGF and FGF-2 $(32,33)$. Also, it 
was shown that EDG-1 and EDG-3 mediated activation of Rho and Rac GTPases and integins polypeptides were required for S1P-mediated chemotaxis in endothelial cells (34). Furthermore, we and others showed that S1P activated protein kinase Akt/ PKB via the EDG-1 coupled to Gi heterotrimeric $G$ protein, and the activity of Akt/ PKB was indispensable for chemotactic responses of endothelial cells following S1P stimulation $(32,35,36)$. Activated Akt/ PKB was shown to associate with the third intracellular loop of EDG-1. In addition, the consensus Akt phosphorylation sequence (RxRxxS/T) was noticed in the third intracellular domain $\left(i_{3}\right)$ of EDG-1, but not in EDG-3, EDG-5, or EDG-8 subtypes of S1P receptors (32). Subsequently, EDG-1 was proven to be a novel physiological substrate for Akt/ PKB by the fact that activated Akt was able to phosphorylate Threonine $236\left(T^{236}\right)$ of EDG-1 both in vitro and in intact cells (32). The Akt-mediate EDG-1 phosphorylation resulted in the transactivation of EDG-1, which was functionally essential for Rac activation, cortical actin assembly, and chemotaxis. Accordingly, a feed-forward reaction involved Akt-mediated EDG-1 phosphorylation for S1P-induced endothelial cell migration was established (32). Indeed, the phosphorylationdeficient EDG-1 mutant, in which T236 was mutated to A, functioned as a dominant-negative reagent to block S1Pmediated Rac activation, chemotactic and angiogenic responses in endothelial cells (32).

Chemotaxis requires the concerted regulation of cytoskeleton remodeling and focal contacts formation. The effects of S1P on cytoskeletal remodeling and focal contact formation were initially observed in 3T3 fibroblasts, in which S1P activated focal adhesion kinase, increased formation of integrin-dependent focal contacts, and Rho-dependent stress fiber assembly (37). Also, S1P treatment affected cytoskeletal architecture and caused neurite retraction in N1E-115 and PC12 neuronal cell lines $(38,39)$. Subsequently, the increased focal contacts and dramatic cytoskeletal changes, including membrane ruffling and stress fibers, were observed in S1P-stimulated endothelial cells $(25,34)$. These S1P-mediated endothelial events required the presence of both EDG- 1 and EDG-3 receptors, and the activities of $G_{i}$ and Rho families of small GTPases. Specifically, S1P/ EDG-1 signaling via the $G_{i} /$ Cdc42 and Rac regulated the membrane ruffling and cortical actin formation, whereas the stress fiber assembly required the Rho small GTPase. Also, EDG-1 mediated Akt activation and the consequent Aktdependent EDG-1 phosphorylation was critical for S1Pinduced membrane ruffling, cortical actin formation, and endothelial chemotaxis $(32,35)$. However, the molec-ular details downstream to Akt-dependent EDG-1 phosphorylation, which ultimately lead to Rac activation and cytoskeletal changes, are poorly understood.

Recently, much attention has been focused on cortactin, a polypeptide required for cross-linking of actin filaments, which was present in the rim of membrane ruffles following FGF-2 stimulation (40). The importance of cortactin-Arp2/3 complexes in S1P mediated chemotaxis was demonstrated by a recent study that overexpression of Arp2/3 binding deficient cortactin mutant inhibited S1P stimulated endothelial migration (41). We and others also observed that cortactin relocalization to membrane ruffling and cell migratory edge of endothelial cells following S1P treatment (Ozaki et al., unpublished observation). It was shown that S1P induced tyrosine-phosphorylation of cortactin by the src family of kinases in endothelial cells (42). However, PP2, a specific inhibitor of the src family of tyrosine kinases, has no effect on S1P-mediated directional migration (Ozaki et al., unpublished observation). Thus, the role of tyrosine phosphorylation of cortactin in $\mathrm{S} 1 \mathrm{P}$-mediated chemotaxis in endothelial cells remains to be determined.

Also, evidence was provided that direct binding of $\mathrm{Cdc} 42$ and Rac1 to the N-terminal regulatory domain of the p21-activated kinase (PAK) stimulated PAK activation and actin reorganization (43). Cortactin is constitutively associated with PAK in resting cells and dissociates from PAK after ligand stimulation. These results suggest that Cdc42/Rac1-dependent activation of PAK may trigger early cytoskeletal rearrangement, at least in part through the regulation of cortactin binding to PAK. Furthermore, it was shown that endothelial myosin light chain kinase (EC MLCK) is stably associated with a complex containing src kinase and cortactin (44). The EC-MLCK-cortactin interaction inhibited cortactin-mediated augmentation of Arp2/ 3-stimulated actin polymerization, implying EC-MLCK cortactin interaction may regulate cytoskeletal remodeling in endothelial cells. Nevertheless, there is no evidence so far which suggests that PAK and/ or EC-MLCK are functionally indispensable in S1P-mediated membrane ruffling and chemotaxis in endothelial cells.

\section{Summary}

EDG-1, the first identified member of EDG family of G-protein coupled receptors, was initially cloned from differentiating human umbilical vein endothelial cells. It was shown that EDG-1 is a high affinity receptor for Sphingosine-1-phosphate, a serum-borne bioactive lipids secreted by thrombotic platelets. Recently, a novel function of S1P in blood vessel development and maturation has been demonstrated. For example, S1P greatly potentiated angiogenesis responses induced by VEGF and FGF. In addition, deletion of EDG-1 resulted in embryonic lethality due to a vascular maturation defect. Also, the molecular details of S1P/EDG-1 signaling cascades have been emerging by efforts from various laboratories. Specifically, it was well documented that at least two distinct signalings are mediated by EDG-1 receptor. S1P/ EDG-1 transiently signals via the $G_{i}$ to regulate MAK 
kinase, phospholipase A2, adenyl cyclase, and protein kinase Akt/ PKB. Alternatively, S1P/ EDG-1 signals via Rho family of small GTP-binding proteins to regulate long-term cellular responses such as adherens junctions assembly, cytoskeletal changes, and chemotaxis in endothelial cells. Characterization of S1P/ EDG-1 signaling will provide knowledge for future modulation of EDG-1 functions, which may offer a novel target for angiogenic therapeutics.

Acknowledgement: This work was supported by Scientist Development Grant (American Heart Association, Northeast Affiliate) to Menq-Jer Lee and NIH grant (DK45659) to Timothy Hla.

\section{References}

(1) Folkman J: Tumor angiogenesis. Adv Cancer Res, 43: 175-203, 1985

(2) Risau W and Flamme I: Vasculogenesis. Annu Rev Cell Dev Biol, 11: 73-91, 1995

( 3 ) Folkman J: Angiogenesis in cancer, vascular, rheumatoid and other disease. Nature Med, 1: 27-31, 1995

( 4 ) Plate KH, Breier G, Weich HA, and Risau W: Vascular endothelial growth factor is a potential tumor angiogenesis factor in human gliomas in vivo. Nature, 359: 845-848, 1992

( 5 ) Stromblad S and Cheresh DA: The role of cell adhesion molecules in angiogenesis. Trends Cell Biol, 6: 462-468, 1996

(6) O'Reilly MS, Holmgren L, Shing Y, Chen C, Rosenthal RA, Moses M, Lane WS, Cao Y, Sage $\mathrm{EH}$, and Folkman J: Angiostatin: a novel angiogenesis inhibitor that mediates the suppression of metastases by a Lewis lung carcinoma. Cell, 79: 315328, 1994

( 7 ) Kim KJ, Li B, Winer J, Armanini M, Gillett N, Philips $\mathrm{HS}$, and Ferrara N: Inhibition of Vascular endothelial growth factor-induced angiogenesis suppresses tumour growth in vitro. Nature, 362: 671-674, 1993

( 8 ) O'Reilly MS, Boehm T, Shing Y, Fukai N, Vasios G, Lane WS, Flynn E, Birkhead JR, Olsen BR, and Folkman $\mathrm{J}$ : Endostatin: an endogenous inhibitor of angiogenesis and tumor growth. Cell, 88:277-285, 1997

(9) Folkman J and Haudenschild C: Angiogenesis in vitro. Nature, 288: 551-556, 1980

(10) Montesano R and Orci L: Phorbol esters induce angiogenesis in vitro from large-vessel endothelial cells. J Cell Physiol, 130: 284-291, 1987

(11) Hla T and Maciag T: An abundant transcript induced in differentiating human endothelial cells encodes a polypeptide with structural similarities to G-proteincoupled receptor. J Biol Chem, 265: 9308-9313, 1990
(12) Tooze J: DNA Tumor Viruses Part 2: Molecular Biology of Tumor Viruses. Cold Spring Harbor Laboratory Press, New York, 1980

(13) Conklin BR and Bourne HR: Structural elements of $G$ alpha subunits that interact with $G$ beta gamma, receptors, and effectors. Cell, 73: 631-641, 1993

(14) Lee MJ, Evans M, and Hla T: The inducible G protein-coupled receptor edg-1 signals via the $\mathrm{G}_{\mathrm{i}} / \mathrm{Mi}$ togen-activated protein kinase pathway. J Biol Chem, 271: 11272-11279, 1996

(15) VanBrocklyn JR, Lee MJ, Menzeleev R, Olivera A, Edsall L, Cuvillier O, Thomas DM, Coopman PJP, Thangade S, Liu CH, Hla T, and Spiegel S: Dual actions of sphingosine-1 phosphate: extracellular through the Gi-coupled receptor Edg-1 and intracellular to regulate proliferation and survival. J Cell Biol, 142: 229-240, 1998

(16) Ancellin N and Hla T: Differential pharmacological properties and signal transduction of the sphingosine 1-phosphate receptors EDG-1, EDG-3, and EDG-5. J Biol Chem, 274:18997-19002, 1999

(17) Lee MJ, VanBrocklyn JR, Thangada S, Liu CH, Hand AR, Menzeleev R, Spiegel S, and Hla T: Sphingosine1-phosphate as a ligand for the $\mathrm{G}$ protein-coupled receptor EDG-1. Science, 279: 1552-1555, 1998

(18) Yatomi Y, Igarashi Y, Yang L, Hisano N, Qi R, Asazuma N, Satoh K, Ozaki Y, and Kume S: Sphingosine 1-phosphate, a bioactive sphingolipid abundantly stored in platelets, is a normal constituent of human plasma and serum. J Biochem, 121: 969973, 1997

(19) Zondag GC, Postma FR, Etten IV, Verlaan I, and Moolenaar WH: Sphingosine 1-phosphate signalling through the G-protein-coupled receptor Edg1. Biochem J, 330:605-609, 1998

(20) Eichholtz T, Jalink K, Fahrenfort I, and Moolenaar WH: The bioactive phospholipid lysophosphatidic acid is released from activated platelets. Biochem J, 291: 677-680, 1993

(21) Moolenaar WH, Kranenburg O, Postma FR, and Zondag GC: Lysophosphatidic acid: G protein signaling and cellular responses. Curr Opin Cell Biol, 9:168-173, 1997

(22) Spiegel S, Cuvillier O, Edsall L, Kohama T, Menzeleev R, Olivera A, Thomas D, Tu Z, Van Brocklyn J, and Wang F: Roles of sphingosine-1-phosphate in cell growth, differentiation, and death. Biochemistry, 63: 69-73, 1998

(23) Hirano S, Kimoto N, Shimoyama Y, Hirohashi S, and Takeichi M: Identification of a neural alpha-catenin as a key regulator of cadherin function and multicellular organization. Cell, 20: 293-301, 1992

(24) Kaibuchi K, Kuroda S, Fukata M, and Nakagawa M: Regulation of cadherin-mediated cell-cell adhesion by the Rho family GTPases. Curr Opin Cell Biol, 
11:591-596, 1999

(25) Lee MJ, Thangada S, Claffey KP, Ancellin N, Liu $\mathrm{CH}$, Kluk M, Volpi M, Sha'afi RI, and Hla T: Vascular endothelial cell adherens junction assembly and morphogenesis induced by sphingosine-1-phosphate. Cell, 99:301-312, 1999

(26) Yap AS, Brieher WM, and Gumbiner BM: Molecular and functional analysis of cadherin-based adherens junctions. Annu Rev Cell Dev Biol, 1997;13:119146, 1997

(27) Garcia JG, Liu F, Verin AD, Birukova A, Dechert MA, Gerthoffer WT, Bamberg JR, and English D: Sphingosine 1-phosphate promotes endothelial cell barrier integrity by Edg-dependent cytoskeletal rearrangement. J Clin Invest, 108:689-701, 2001

(28) Lee OH, Kim YM, Lee YM, Moon EJ, Lee DJ, Kim $\mathrm{JH}, \mathrm{Kim} \mathrm{KW}$, and Kwon YG: Sphingosine 1-phosphate induces angiogenesis: its angiogenic action and signaling mechanism in human umbilical vein endothelial cells. Biochem Biophys Res Commun, 264:743-750, 1999

(29) Passaniti A, Taylor RM, Pili R, Guo Y, Long PV, Haney JA, Pauly RR, Grant DS, and Martin GR: A simple, quantitative method for assessing angiogenesis and antiangiogenic agents using reconstituted basement membrane, heparin, and fibroblast growth factor. Lab Invest, 67:519-528, 1992

(30) Bach TL, Barsigian C, Chalupowicz DG, Busler D, Yaen $\mathrm{CH}$, Grant DS, and Martinez J: VE-Cadherin mediates endothelial cell capillary tube formation in fibrin and collagen gels. Exp Cell Res, 238:324334, 1998

(31) Carmeliet $P$, Lampugnani MG, Moons L, Breviario $\mathrm{F}$, Compernolle V, Bono F, Balconi G, Spagnuolo R, Oostuyse B, Dewerchin M, Zanetti A, Angellilo A, Mattot V, Nuyens D, Lutgens E, Clotman F, de Ruiter MC, Gittenberger-de Groot A, Poelmann R, Lupu F, Herbert JM, Collen D, and Dejana E: Targeted deficiency or cytosolic truncation of the VEcadherin gene in mice impairs VEGF-mediated endothelial survival and angiogenesis. Cell, 98:147157, 1999

(32) Lee MJ, Thangada S, Paik JH, Sapkota GP, Ancellin N, Chae SS, Wu M, Morales-Ruiz M, Sessa WC, Alessi DR, and Hla T: Akt-mediated phosphorylation of the G protein-coupled receptor EDG-1 is required for endothelial cell chemotaxis. Mol Cell, 8:693-704, 2001

(33) Liu F, Verin AD, Wang P, Day R, Wersto RP, Chrest FJ, English DK, and Garcia JG: Differential regulation of sphingosine-1-phosphate- and VEGF-induced endothelial cell chemotaxis. Involvement of G(ialpha2)-linked Rho kinase activity. Am J Respir Cell Mol Biol, 24:711-719, 2001

(34) Paik JH, Chae Ss, Lee MJ, Thangada S, and Hla T:
Sphingosine 1-phosphate-induced endothelial cell migration requires the expression of EDG-1 and EDG-3 receptors and Rho-dependent activation of $\alpha_{v} \beta_{3}$ - and $\beta_{1}$-containing integrins. J Biol Chem, 276:11830-11837, 2001

(35) Morales-Ruiz M, Lee MJ, Zollner S, Gratton JP, Scotland R, Shiojima I, Walsh K, Hla T, and Sessa WC: Sphingosine 1-phosphate activates Akt, nitric oxide production, and chemotaxis through a Gi protein/phosphoinositide 3-kinase pathway in endothelial cells. J Biol Chem, 276:19672-19677, 2001

(36) Igarashi J, Bernier SG, and Michel T: Sphingosine 1-phosphate and activation of endothelial nitric-oxide synthase. differential regulation of Akt and MAP kinase pathways by EDG and bradykinin receptors in vascular endothelial cells. J Biol Chem, 276:12420-12426, 2001

(37) Wang F, Nobes CD, Hall A, and Spiegel S: Sphingosine 1-phosphate stimulates rho-mediated tyrosine phosphorylation of focal adhesion kinase and paxillin in Swiss $3 T 3$ fibroblasts. Biochem J, 324:481-488, 1997

(38) Postma FR, Jalink K, Hengeveld T, and Moolenaar $\mathrm{WH}$ : Sphingosine-1-phosphate rapidly induces Rho-dependent neurite retraction: action through a specific cell surface receptor. EMBO J, 15:23882392, 1996

(39) Sato K, Tomura H, Igarashi Y, Ui M, Okajima F: Exogenous sphingosine 1-phosphate induces neurite retraction possibly through a cell surface receptor in PC12 cells. Biochem Biophys Res Commun, 240:329-334, 1997

(40) Zhan X, Hu X, Hampton B, Burgess WH, Friesel R, Maciag T: Murine cortactin is phosphorylated in response to fibroblast growth factor-1 on tyrosine residues late in the $\mathrm{G} 1$ phase of the BALB/c $3 T 3$ cell cycle. J Biol Chem, 268:24427-24431, 1993

(41) Li Y: The role of cortactin-mediated actin polymerization in S1P-induced cell migration and tube formation of endothelial cells. Mol Biol Cell, 13:312a, 2002

(42) Vouret-Craviari V, Bourcier C, Boulter E, and van Obberghen-Schilling E: Distinct signals via Rho GTPases and Src drive shape changes by thrombin and sphingosine-1-phosphate in endothelial cells. J Cell Sci, 115:2475-2484, 2002

(43) Vidal C, Geny B, Melle J, Jandrot-Perrus M, and Fontenay-Roupie M: Cdc42/Rac1-dependent activation of the $\mathrm{p} 21$-activated kinase (PAK) regulates human platelet lamellipodia spreading: implication of the cortical-actin binding protein cortactin. Blood, 100:4462-4469, 2002

(44) Dudek SM, Birukov KG, Zhan X, and Garcia JG: Novel interaction of cortactin with endothelial cell myosin light chain kinase. Biochem Biophys Res Commun, 298:511-519, 2002 